Research Article

\title{
Novel Validated RP-HPLC Method for Determination of Rivaroxaban in Bulk and its Pharmaceutical Dosage Form
}

\author{
M. M. Eswarudu*, A. Lalitha devi, K. Pallavi, P. Srinivasa Babu, S. Nandini Priya, SK. Sabeeha Sulthana. \\ Department of Pharmaceutical Analysis, Vignan Pharmacy College, Vadlamudi (V), Chebrolu(M), Guntur (Dist), Andhra Pradesh, India. \\ *Corresponding author's E-mail: eswarmunnangi@gmail.com
}

Received: 11-06-2020; Revised: 16-08-2020; Accepted: 23-08-2020.

DOI: $10.47583 /$ ijpsrr.2020.v64i01.033 \begin{abstract}
A simple, specific, accurate, and precise reverse phase high performance liquid chromatographic (RP-HPLC) method was developed and validated for the quantification of Rivaroxaban in Bulk drug and Pharmaceutical dosage form. The quantification is carried out with a Nucleosil C18, $(250 \times 4.6 \mathrm{~mm}, 5 \mu \mathrm{m})$ column maintained at room temperature with mobile phase consisted of a mixture of acetonitrile and water in the ratio of $50: 50(\mathrm{v} / \mathrm{v})$ delivered at a flow rate of $1.0 \mathrm{ml} / \mathrm{min}$ and effluents were monitored at $251 \mathrm{~nm}$ through PDA detector. The total run time was set at $7 \mathrm{~min}$. The retention time of Rivaroxaban was found to be $4.893 \mathrm{~min}$. The method was validated as per ICH guidelines, parameters like linearity, accuracy, precision, specificity, limit of detection, limit of quantification and robustness. The linearity was in the range of $5-50 \mu \mathrm{g} / \mathrm{ml}$ with correlation co-efficient of 0.9992 . The recovery of rivaroxaban was found to be $98.84 \%$. Limit of detection and limit of quantification were found $0.054 \mu \mathrm{g} / \mathrm{ml}$ and $0.164 \mu \mathrm{g} / \mathrm{ml}$ respectively. The proposed method was successfully applied for the quantitative determination of Rivaroxaban in tablet dosage form in quality control testing laboratories.
\end{abstract}

Keywords: Rivaroxaban, HPLC, Method validation, Tablets dosage form.

\section{INTRODUCTION}

ivaroxaban (RIV; Figure 1) is an oral oxazolidinonebased anticoagulant; it is a potent and selective direct inhibitor of factor Xa for the prevention of venous thromboembolism in adult patients after total hip replacement or total knee replacement surgery. ${ }^{1}$ Chemically it is 5-chloro- $\mathrm{N}-[[(5 \mathrm{~S})-2-0 x 0-3-$ [4-(3oxomorpholin-4-yl) phenyl]-1, 3-oxazolidin-5-yl] methyl] thiophene- 2-carboxamide It is an empirical formula $\mathrm{C}_{19} \mathrm{H}_{18} \mathrm{Cl} \mathrm{N} \mathrm{O}_{5} \mathrm{~S}$ and molecular weight of $435.882 \mathrm{~g} / \mathrm{mol} .{ }^{2-3}$<smiles>O=C(NC[C@H]1CN(c2ccc(N3CCOCC3=O)cc2)C(=O)O1)c1ccc(Cl)s1</smiles>

Figure 1: Chemical structure of Rivaroxaban

Literature survey revealed that few analytical methods have been reported for estimation of Rivaroxaban individually or in combination with other drugs. The reported methods are Spectrophotometric ${ }^{4}, \mathrm{RP}^{-H P L C} \mathrm{C}^{5-17}$ and HPTLC ${ }^{18}$ methods. The present study was aimed to develop a simple, sensitive, rapid and precise RP-HPLC method for estimation of Rivaroxaban. The analytical method was validated according to $\mathrm{ICH}$ validation parameters. $^{19-21}$

\section{MATERIALS AND METHODS}

\section{Chemicals and reagents}

Pure sample of Rivaroxaban obtained from Hetero drugs private Itd, Hyderabad, India. The marketed formulation of Xarelto-10 mg tablets (Rivaroxaban $10 \mathrm{mg} /$ tablet) Manufactured by Bayer Zydus AG, Germany, imported and marketed by Bayer Zydus Pharma Limited, Maharashtra, India were procured from local pharmacy store. HPLC grade of acetonitrile were procured from SD Fine Chemicals Ltd., Mumbai, India. Methanol of HPLC grade was purchased from Merck, Mumbai, India. HPLC grade water was obtained by double distillation and purified additionally with Milli-Q water purification system.

\section{Instrumentation}

The analysis was performed by using a chromatographic system, Agilent HPLC comprised of a 1260 Quaternary pump, a $20 \mu \mathrm{L}$ injection loop and a 1260 photo diode array detector and running on $\mathrm{E}-\mathrm{Z}$ Chrome software with a reverse phase Nucleosil $C_{18}$ column having $250 \times 4.6 \mathrm{~mm}$ internal diameter, $5 \mu \mathrm{m}$ particle size. UV-Visible Spectrophotometer (Elico SL-210-) Shimadzu electronic balance (AX-200) was used for weighing purpose.

\section{Chromatographic Conditions}

Rivaroxaban was analyzed with Nucleosil $\mathrm{C}_{18}$ column (250 x $4.6 \mathrm{~mm}, 5 \mu \mathrm{m}$ particle size) for the chromatographic separation and column was maintained at ambient temperature. The mobile phase was composed of a mixture of acetonitrile and water in the ratio of 50:50 v/v and it was delivered at a flow rate of $1.0 \mathrm{~mL} / \mathrm{min}$ and detection was monitored at $251 \mathrm{~nm}$ with PDA detector. 
Mobile phase was used as diluent. Injection volume was 20 $\mu \mathrm{l}$. The run time was $7 \mathrm{~min}$. The retention time of Rivaroxaban was found to be $4.893 \mathrm{~min}$.

Table 1: Optimized chromatographic conditions

\begin{tabular}{|l|l|}
\multicolumn{1}{|c|}{ Parameter } & \multicolumn{1}{c|}{ Condition } \\
\hline $\begin{array}{l}\text { Mobile phase and } \\
\text { ratio }\end{array}$ & $\begin{array}{l}\text { Acetonitrile: Water }(50: 50 \% \\
\mathrm{v} / \mathrm{v})\end{array}$ \\
\hline Column & $\begin{array}{l}\text { Nucleosil } \mathrm{C}_{18} 250 \mathrm{~mm} \times 4.6 \mathrm{~mm} ; \\
5.0 \mu \mathrm{m}\end{array}$ \\
\hline Wave length & $251 \mathrm{~nm}$ \\
\hline Column Temperature & $\mathrm{Ambient}$ \\
\hline Injection volume & $20 \mu \mathrm{L}$ \\
\hline Flow rate & $1.0 \mathrm{~min} / \mathrm{ml}$ \\
\hline Run Time & $7 \mathrm{minutes}$ \\
\hline
\end{tabular}

\section{Preparation of Standard stock solution}

Accurately weighed and transferred $10 \mathrm{mg}$ of Rivaroxaban working standard into $10 \mathrm{ml}$ clean and dry volumetric flask, add $5 \mathrm{ml}$ of Acetonitrile and sonicated for 5 minutes and made up to the final volume with diluent. From the above stock solutions, $1 \mathrm{ml}$ was pipette out in to a $10 \mathrm{ml}$ volumetric flask and then made up to the final volume with same diluent, and it gives $100 \mu \mathrm{g} / \mathrm{ml}$ solution.

\section{Preparation of Sample Solution}

Accurately 20 tablets were weighed individually and the average weight was calculated and powdered. The tablet powder equivalent to $10 \mathrm{mg}$ of Rivaroxaban and it was transferred into a $10 \mathrm{ml}$ volumetric flask, to that $5 \mathrm{ml}$ of diluent was added and sonicated for 5 minutes at controlled temperature to dissolve the powder, further the volume was made up with diluent, and filtered through $0.45 \mu$ membrane filter. From this solution $1 \mathrm{ml}$ was diluted to $10 \mathrm{ml}$ with the same diluent to give a concentration of $100 \mu \mathrm{g} / \mathrm{ml}$ of Rivaroxaban.

\section{Method Development and Optimization}

The optimized HPLC conditions several mobile phases of different compositions were tested to develop an optimization of chromatographic conditions such as tailing factor, good peak shape, and theoretical plates. For the selection of the mobile phase primarily methanol: acetonitrile, methanol: water, acetonitrile: water has been tested for different compositions, flow rates and ratios. Finally, mobile phase consisting a mixture of acetonitrile: water $(50: 50 \% \mathrm{v} / \mathrm{v})$ at a flow rate of $1.0 \mathrm{ml} / \mathrm{min}$ was found to be satisfactory and proper system suitability parameter results were obtained. ${ }^{22}$

\section{Method Validation}

The method was validated for Specificity, linearity, accuracy, precision, limit of detection, limit of quantification and robustness by following procedures.

\section{System Suitability}

System suitability is an integral part of the chromatographic system. It is verification of resolution, capacity factor, tailing factor, theoretical plate count, relative retentions etc. are calculated and compared with standard specification of system. ${ }^{22}$

\section{Specificity}

Specificity is the ability to assess unequivocally the analyte in the presence of components which may be expected to be present. The specificity of an analytical method is to determine the effect of excipients and other additives that are generally present in the formulation. The test results obtained were contrasted with the results of standard drug. ${ }^{23}$

\section{Linearity}

Linearity is the ability (within specified range) to obtain test results are directly proportional to the concentration of analyte in the sample. Linearity is evaluated by visual inspection of plot of signal as a function of analyte concentration. If there is a linear relationship test results are calculated by regression line by method of least squares. ${ }^{23}$

The linearity of the method was determined at six concentration levels ranging from $5-50 \mu \mathrm{g} / \mathrm{ml}$ for Rivaroxaban. Evaluation of the drug was performed with PDA detector at $251 \mathrm{~nm}$, peak area was recorded for all the peaks. The correlation coefficient value of Rivaroxaban was 0.9992. The results shown that an excellent correlation exists between peak area and concentration of drug within the concentration range indicated. ${ }^{23}$

\section{Range}

The range of analytical procedure is the interval between the upper and lower concentration of analyte in the sample. ${ }^{23}$

\section{Accuracy}

Accuracy of analytical method is 'measure of how close the experimental value to the true value' accuracy of the method was determined by standard addition method. A known amount of standard drug is added to the fixed amount of pre-analyzed injection solution. Percent recovery is calculated by comparing the area before and after addition of the standard drug. The standard addition method is performed at $10 \%, 30 \%$ and $50 \%$ level. The solutions are analyzed in triplicate at each level as per the proposed method. ${ }^{23}$

The accuracy of the method was determined by calculating recovery of Rivaroxaban by the method of standard addition. Known amount of Rivaroxaban was added to a pre-quantified sample solution and the amount of Rivaroxaban was estimated by measuring the peak area ratios and by fitting these values to the straight-line equation of calibration curve. The recovery studies were carried out three times over the specified concentration 
range of $10 \%, 30 \%$ and $50 \%$ levels. The amount of Rivaroxaban was estimated by measuring the peak area ratios by fitting these values to the straight-line equation of calibration curve. From the above determination, percentage recovery and standard deviation of percentage recovery were calculated..$^{23}$

\section{Precision}

The closeness of agreement (degree of scatter) between a series of measurements obtained from multiple sampling of the same homogenous sample under the prescribed conditions. Precision may be considered at three levels: repeatability, intermediate precision and reproducibility. The intra-day precision study of Rivaroxaban was carried out by estimating the correspondence responses six times on the same day with $100 \%$ concentration and inter-day precision study of Rivaroxaban was carried out by estimating the correspondence responses six times next day with $100 \%$ concentration. ${ }^{23}$

\section{Limit of detection and Limit of Quantification}

Limit of detection (LOD) is defined as the lowest concentration of analyte that gives a detectable response. Limit of Quantification (LOQ) is defined as the lowest concentration of analyte that can be quantified with a specified level of accuracy and precision. For this study, six replicates of the analyte at lowest concentration are measured and quantified.

The limit of detection (LOD) and limit of quantification (LOQ) of the developed method were determined by injecting progressively low concentrations of the standard solution using the developed HPLC method. ${ }^{23}$

\section{Robustness}

The robustness of an analytical procedure is a measure of its capacity to remain unaffected by small, but deliberate variations in method parameters and provides an indication of its reliability during normal usage. The evaluation of robustness should be considered during the development phase and depends on the type of procedure under study. It should show the reliability of an analysis with respect to deliberate variations in method parameters. The robustness of the proposed method is estimated by changing flow rate of the mobile phase and composition of the mobile phase. ${ }^{19}$

\section{RESULTS AND DISCUSSION}

The HPLC procedure was optimized with a view to develop an accurate assay method for the determination of Rivaroxaban in bulk and pharmaceutical dosage form by using Nucleosil C18 (250 x 4.6 mm internal diameter; $5 \mu \mathrm{m}$ particle size) column with mobile phase of acetonitrile and water in the ratio of 50:50 v/v. The flow rate of mobile phase at $1.0 \mathrm{ml} / \mathrm{min}$ and the component was monitored and detected with PDA detector at $251 \mathrm{~nm}$. The eluted drug peak with good shape and well resolved. The results of optimized chromatographic conditions were shown in Table 1. The retention time, number of theoretical plates and tailing factor of Rivaroxaban was found to be 4.893 min., 13924 and 1.002 respectively, which indicates efficient performance of the column. The method was linear in the range of $5-50 \mu \mathrm{g} / \mathrm{ml}$ for Rivaroxaban with correlation coefficient of 0.9992 . The regression equation of Rivaroxaban concentration over its peak area ratio was found to be $Y=147199 x$, where $X$ is the concentration of Rivaroxaban and $Y$ is the respective peak area. The linearity results were shown in Table 2 and Figure 2.

Table 2: Linearity results of Rivaroxaban

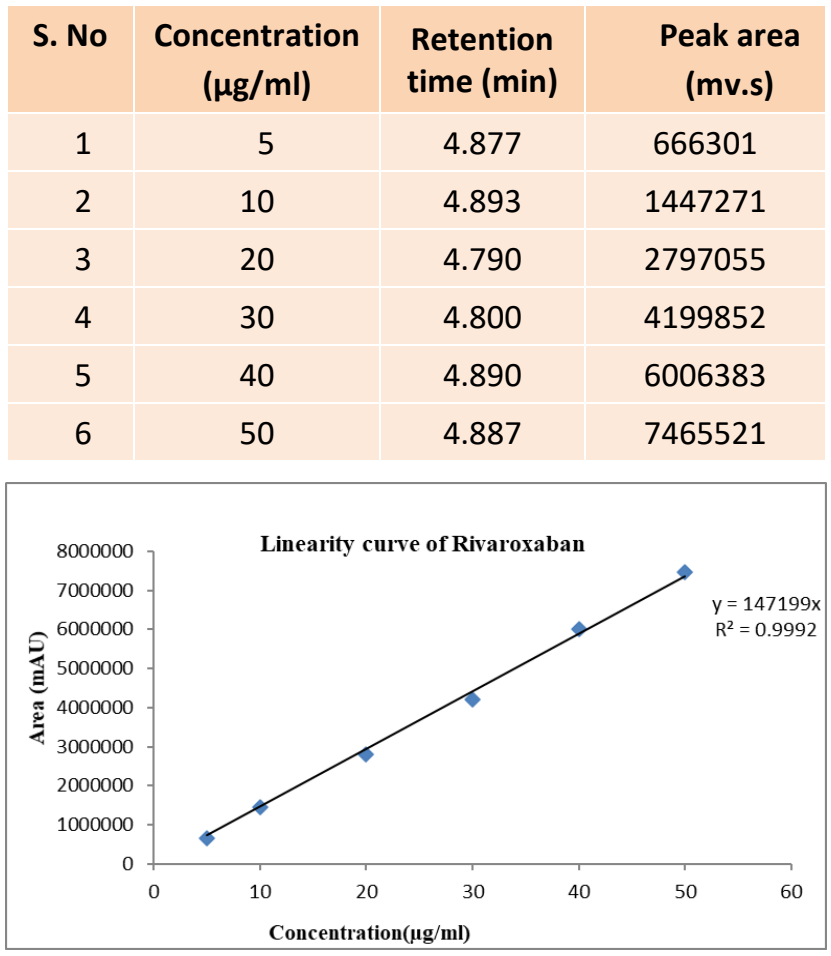

Figure 2: Linearity curve of Rivaroxaban

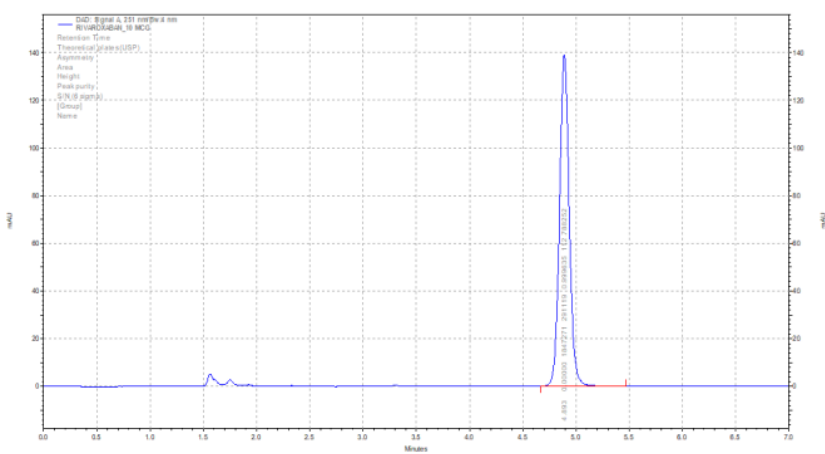

Figure 3: Chromatogram of Rivaroxaban

The mean \% recoveries was found to be $98.84 \%$ which indicate the method is accurate. The accuracy results were shown in Table 3. The \% RSD for intra-day precision and inter-day precision for Rivaroxaban were found to be 0.18 and 0.20 , the values were less than $2 \%$ which indicate the method is precise. The results of precision studies were shown in Table 4. The limit of detection (LOD) and limit of quantification (LOQ) for Rivaroxaban were found to be $0.054 \mu \mathrm{g} / \mathrm{ml}$ and $0.164 \mu \mathrm{g} / \mathrm{ml}$, which indicate the sensitivity of the method. 
Table 3: Accuracy result of Rivaroxaban

\begin{tabular}{|c|c|c|c|c|}
\hline $\begin{array}{c}\text { Spike } \\
\text { Level }\end{array}$ & $\begin{array}{c}\text { Amount } \\
\text { added } \\
(\mu \mathrm{g} / \mathrm{ml})\end{array}$ & $\begin{array}{c}\text { Amount } \\
\text { found } \\
(\mu \mathrm{g} / \mathrm{ml})\end{array}$ & $\begin{array}{c}\% \\
\text { recovery }\end{array}$ & $\begin{array}{c}\text { mean } \\
\% \\
\text { recovery }\end{array}$ \\
\hline $10 \%$ & 10 & 9.91 & 99.1 & \\
\hline $10 \%$ & 10 & 9.78 & 97.8 & 98.20 \\
\hline $10 \%$ & 10 & 9.75 & 97.5 & \\
\hline $30 \%$ & 30 & 9.97 & 99.7 & \\
\hline $30 \%$ & 30 & 9.94 & 99.4 & 99.64 \\
\hline $30 \%$ & 30 & 9.97 & 99.7 & \\
\hline $50 \%$ & 50 & 9.78 & 97.8 & \\
\hline $50 \%$ & 50 & 9.92 & 99.2 & 98.6 \\
\hline $50 \%$ & 50 & 9.89 & 98.9 & \\
\hline
\end{tabular}

The robustness was performed for the flow rate variations from $1 \mathrm{ml} / \mathrm{min}$ to $1.2 \mathrm{ml} / \mathrm{min}$. The method is robust only in less flow condition $\pm 2 \%$. The results are summarized on evaluation of the above results, it can be concluded that the variation in flow rate affected the method significantly. Hence it indicates that the method is robust even by change in the flow rate $\pm 0.2 \mathrm{ml} / \mathrm{min}$. The method is robust only in less flow condition. The typical variations studied under this parameter was mobile phase flow rate. Overall $\%$ RSD was found to be less than $2 \%$ for all the variations which indicates that the proposed method is robust.

Table 4: Intraday and Inter day Precision Results of Rivaroxaban

\begin{tabular}{|c|c|c|c|c|}
\hline \multirow{2}{*}{ S. No. } & \multicolumn{2}{|c|}{ Intraday Precision } & \multicolumn{2}{|c|}{ Inter day Precision } \\
\hline & RT & Peak Area & RT & Peak Area \\
\hline 1 & 4.800 & 4199852 & 4.800 & 4199763 \\
\hline 2 & 4.801 & 4198763 & 4.801 & 4198789 \\
\hline 3 & 4.801 & 4192314 & 4.801 & 4192216 \\
\hline 4 & 4.801 & 4189216 & 4.801 & 4188216 \\
\hline 5 & 4.800 & 4186413 & 4.800 & 4186512 \\
\hline 6 & 4.800 & 4179897 & 4.800 & 4176342 \\
\hline Average & & 4191076 & & 4190306 \\
\hline Std. Dev & & 7587.0 & & 8704.0 \\
\hline \% RSD & & 0.18 & & 0.20 \\
\hline
\end{tabular}

The summary of system suitability parameters and validation parameters were shown in Table 5 . Validated method was applied for the determination of Rivaroxaban in commercial tablet formulation that was obtained by injected 3 replicates of the sample solutions. The amount of drug and percentage of assay was found to be 14.84 $\mathrm{mg} /$ tablet and $98.933 \%$. Typical chromatogram of drug Rivaroxaban was shown in Figure 3. No interfering peaks were found in the chromatogram of the formulation within the run time indicating that excipients used in the formulation did not interfere with the estimation of the drug by the proposed method.
Table 5: System Suitability and Validation Parameters

\begin{tabular}{|c|l|c|}
\hline S. No. & \multicolumn{1}{|c|}{ Parameter } & Results \\
\hline 1 & Linearity range $(\mu \mathrm{g} / \mathrm{ml})$ & $5-50$ \\
\hline 2 & Correlation coefficient $\left(\mathrm{r}^{2}\right)$ & 0.9992 \\
\hline 3 & Retention times (min) & 4.893 \\
\hline 4 & Theoretical plates (N) & 13924 \\
\hline 5 & Tailing factor & 1.002 \\
\hline 6 & Mean \% recovery (\%) & 98.84 \\
\hline 7 & Repeatability (\% RSD) & 0.18 \\
\hline 8 & Reproducibility (\% RSD) & 0.20 \\
\hline 9 & LOQ ( $\mu$ g/ml) & 0.054 \\
\hline 10 & Robustness (\% RSD) & 0.164 \\
\hline 11 & Assay (\%) & 0.239 \\
\hline
\end{tabular}

\section{CONCLUSION}

Proposed Study describes new HPLC method for the estimation of Rivaroxaban bulk and in its tablet formulation. The method was validated and found to be simple, sensitive, accurate, precise and robust. Percentage of recovery shows that the method is free from interference of the excipients used in the formulation. Therefore, the proposed method can be used for routine analysis of estimation of Rivaroxaban in regular quality control testing laboratories.

Acknowledgements: The authors are thankful to Management of Vignan Pharmacy College, Vadlamudi, India for providing necessary facilities for carryout the research work. And authors also thankful to Hetero drugs private Itd, Hyderabad, India for providing the working standard drug Rivaroxaban.

\section{REFERENCES}

1. Duggan ST, Rivaroxaban; American Journal of Cardiovascular Drugs, 12(1), 2012, 57-72.

2. Satya prasad B, Jayakumar S, Quantification of anticoagulants Dabigatran, Rivaroxaban, and Prasugrel by Chromatographic and Spectrometric techniques - Review, Asian J Pharm Clin Res, 12(4), 2019, 1-8.

3. FDA, Xarelto Approval History. http://www.drugs.com/history/xarelto.html (accessed September 1, 2014).

4. Chandra Bala S, Vankayapati Hima Bind, Mittapati Rupa D, Anaparthi S, Development and Validation of UV Spectroscopic method for determination of Rivaroxaban, Der Pharma Chemica, 5(4), 2013, 1-5.

5. Yashpalsinh N Girase, Srinivas Rao V, Dipti Soni Development and Validation of Stability Indicating RP-HPLC Method for Rivaroxaban and Its Impurities, SOJ Bio chem, 4(1), 2018, 16. 
6. Suraj Sahoo, Suman Kumar M, Assay comparison of Rivaroxaban by new HPLC method with an existing method in tablet dosage form, Pharmaceutical and biological evaluations, 4 (3), 2017, 180-182.

7. Amelia M. Avachat, RP-HPLC Method development and validation for the estimation of Rivaroxaban in bulk and tablet dosage forms, World journal of pharmacy and pharmaceutical sciences, 6 (8), 2017, 1775-1784.

8. Arpitha Sunny, Development of New Analytical Method and Validation for Quantitative Estimation of Rivaroxaban in Formulation and Bulk Drug, International Journal of Scientific Research and education, 5(5), 2017, 6469-6478.

9. Sunitha VS, Veera Venkata Satyanarayana $P$, and Chandra bala Sekaran, Application of Stability Indicating HPLC Method with UV Detector to the Analysis of Rivaroxaban in Bulk and Tablet Dosage Form, Chemical Science Transactions 3(4), 2014, 1546-1554.

10. Pinaz A, Kasad, Photolytic-Thermal Degradation Study and Method Development of Rivaroxaban By RP-HPLC, International Journal of PharmTech Research, 5(3), 2013, 1254-1263.

11. Pinaz A, Murali Krishna KS, Base Degradation Study and Method Development of Rivaroxaban by RP-HPLC in Bulk Asian Journal of Pharmacy and Technology, 3(3), 2013, 98101.

12. Mustafa Çelebier, Photolytic-Thermal Degradation Study and Method Development of Rivaroxaban By RP-HPLC, Brazilian Journal of Pharmaceutical Sciences, 49(2), 2013, 216-220.

13. Badroon T, Tuba Reçber, Engin Koçak, Sacide Altınöz, and Sedef Kır, Development and Validation of stability indicating assay by HPLC method for estimation of Rivaroxaban, International Journal of Bio-Pharma Research, 8(5), 2019, 2582-2586.

14. Shivashankar V, Gandhimathi, M, Ravi TK, International Journal of Pharmacy and Analytical Research, Development and validated RP-HPLC method for estimation of Rivaroxaban in pharmaceutical formulation, International
Journal of Pharmacy and Analytical Research. 4(4), 2015, 106-110.

15. Basima Arous, Al-Mardini, M.A., Kara bet F, Development and validation of liquid chromatographic method for the analysis of Rivaroxaban and determination of its production related impurities. Pharmaceutical Chemistry Journal, 52 (5), 2018, 483-490.

16. Swarup S. Prabhune, Enantiomeric Separation of Rivaroxaban by A Chiral Liquid Chromatographic Method, International Journal of Pharmacy and Pharmaceutical Sciences, 7(2), 2015, 399-402.

17. Manjunatha $\mathrm{DH}$, Determination of Rivaroxaban in pure, pharmaceutical formulation and human plasma samples by RP-HPLC." International journal of advance in pharmaceutical analysis, 5(3), 2015, 65-68.

18. Darshna V, Pinak $P$, High performance thin layer chromatographic method with densitometry analysis for the determination of Rivaroxaban from its tablet dosage form. International journal of pharmacy and pharmaceutical science, 6(6), 2014, 383-386.

19. Lavanya G, Sunil M, Eswarudu MM, Eswaraiah MC, Harisudha $\mathrm{K}$ and Spandana BN: Analytical Method Validation: An Updated Review. Int J Pharm Sci Res 4(4), 2013, 1280-1286.

20. ICH Harmonized Tripartite Guideline, Validation of analytical procedures: Text and methodology, Q2 (R1), International Conference on Harmonization, Geneva. 2005, 1-13.

21. ICH Harmonized Tripartite Guideline Stability Testing of New Drug Substances and Products Q1A (R2), International Conference on Harmonization, Geneva. 2003, 1-18.

22. Sankar PR, Swathi $\mathrm{V}$ and Babu PS, Development and validation of novel UV and RP-HPLC methods for determination of Cilnidipine (a new generation Ca channel blocker) in pharmaceutical dosage form. Int J Pharm Sci \& Res, 10(4), 2019, 1886-1894.

23. Mukkanti Eswarudu M, Lakshmana Rao A, Vijay K. Stability Indicating RP-HPLC Method for Simultaneous Quantification of Ezetimibe and Glimepiride in Bulk and Pharmaceutical Dosage form., Indo Am. J. P. Sci, 5(11), 2018, 11268-11276.

Source of Support: None declared.

Conflict of Interest: None declared.

For any question relates to this article, please reach us at: editor@globalresearchonline.net New manuscripts for publication can be submitted at: submit@globalresearchonline.net and submit_ijpsrr@rediffmail.com 